PHYSICAL REVIEW A 95, 069903(E) (2017)

\title{
Publisher's Note: Robust paths to realize nonadiabatic holonomic gates \\ [Phys. Rev. A 95, 052349 (2017)]
}

G. F. Xu, P. Z. Zhao, D. M. Tong, and Erik Sjöqvist

(Received 2 June 2017; published 9 June 2017)

DOI: 10.1103/PhysRevA.95.069903

This paper was published online on 30 May 2017 with an error in a source listing in the abstract and in Ref. [29]. The seventh line of the abstract should read as "... resonance single-shot scheme [G. F. Xu et al., Phys. Rev. A 92, 052302 (2015); ...." Reference [29] should read as “G. F. Xu, C. L. Liu, P. Z. Zhao, and D. M. Tong, Phys. Rev. A 92, 052302 (2015).” The source listing and the reference have been corrected as of 2 June 2017. The source listing and the reference are correct in the printed version of the journal. 